\title{
As Compras Não Planejadas em Supermercados: a Importância do Tempo e da Organização da Loja na Determinação dos Gastos
}

\author{
Claudio Felisoni de Angelo \\ João Paulo de Lara Siqueira \\ Luiz Paulo Lopes Fávero
}

\begin{abstract}
Resumo
As transformações que vêm ocorrendo no mercado de consumo brasileiro têm exigido das empresas comerciais atenção cada vez maior para os aspectos operacionais. O presente trabalho procura analisar de modo particular como o tempo de permanência nas áreas de compra e a importância atribuída à disposição dos produtos nos corredores e gôndolas afetam os gastos totais, dando especial atenção aos gastos não planejados. Partindo de um levantamento realizado pelo Programa de Administração de Varejo (PROVAR) no segundo semestre de 2001, construíram-se dois modelos: um para o grupo dos indivíduos que gastaram mais que o planejado e outro para os que consumiram de maneira igual ou abaixo do previamente estabelecido por eles. Verificou-se que os gastos são muito sensíveis ao tempo de permanência na loja. Quanto à disposição dos produtos, observou-se que, para o grupo daqueles que gastaram menos que o planejado, a colocação dos produtos complementares próximos reduz os gastos.
\end{abstract}

Palavras-chaves: marketing; compra por impulso; varejo; supermercados.

\section{Abstract}

As a result of the many changes that are happening in the Brazilian retail, firms are being forced to pay close attention to their operations. This paper analyses how layout and the time spent inside the stores impact the total expenditure of the consumers, especially those that were not previously planned. Using data from a field research carried out by Programa de Administração de Varejo (PROVAR) in the second semester of 2001, two models were built: the first with the group of interviewed people who spent more than previously planned and the second with the consumers that spent the same or less than planned. It was possible to observe that the expenditure is very sensible to the time people stay inside the store. In relation to the layout of the products, it was observed that the group that spent less than planned reduced their purchase if complementary goods were put together.

Key words: marketing; impulse buying; retail; supermarkets. 


\section{INTRODUÇÃO}

O varejo brasileiro vem passando por intenso processo de transformação. Durante muitas décadas os aspectos operacionais relacionados à administração varejista foram negligenciados e as vastas e rentáveis possibilidades oferecidas pelo mercado financeiro permitiam que as empresas do setor compensassem com grande facilidade seus problemas operacionais. De fato, pouca atenção se dava às atividades de comercialização propriamente ditas, uma vez que as aplicações financeiras propiciavam ganhos muitas vezes superiores aos conseguidos pela aparentemente simples operação de compra e venda de mercadorias (Blecher, 2001).

A política de redução drástica do ritmo inflacionário, introduzida em 1994 com o Plano Real, provocou mudanças significativas em toda a dinâmica da economia brasileira e reestruturou de imediato o mercado de consumo. As empresas varejistas, que sustentavam sua rentabilidade com as operações financeiras, passaram a não mais contar com essa fonte de recursos. Com seus ganhos fortemente diminuídos, restava às empresas de varejo assegurar seus lucros a partir do exercício quase exclusivo de suas operações mercantis.

No entanto a estabilidade de preços também estimulou vigorosamente a competição e tal fato pode ser explicado pela combinação de diversos fatores. O primeiro aspecto relevante diz respeito à ampliação das importações de bens de consumo, ocorrida como parte da própria lógica do Plano Real. O segundo ponto associa-se à maior consciência de valor por parte do consumidor. As baixas taxas de inflação, ou até mesmo deflação em alguns momentos, permitiram aos consumidores formar idéias mais claras sobre valor dos produtos comprados ou dos serviços contratados. Finalmente, a estabilidade da economia brasileira trouxe para o mercado de consumo cadeias varejistas estrangeiras, que até então apresentavam certos receios em relação a possíveis investimentos diretos no Brasil (PROVAR, 2001). E, paralelamente a todas essas mudanças, também ocorreu uma valorização do consumidor, cujo código de defesa, implantado poucos anos antes, começava a surtir seus efeitos.

Nesse cenário, as empresas comerciais foram forçadas a concentrar seu foco nos aspectos diretamente ligados à operação. Essa orientação materializou-se em termos de ações basicamente em duas direções: maior preocupação com os elementos geradores de custos e maior interesse em conhecer os elementos condicionantes dos diversos mercados. 
Embora essa reflexão possa provavelmente aplicar-se a todos os segmentos que compõem o mercado de consumo brasileiro, não há dúvidas de que o ramo composto pelos supermercados merece atenção especial (PROVAR, 2001). Atualmente, grande parte da comercialização de bens no Brasil se realiza por meio desse tipo de comércio e os supermercados vêm expandindo os seus ramos de atuação e ampliando o sortimento dos produtos oferecidos. As suas atividades, outrora restritas à comercialização de produtos alimentares e de higiene e limpeza, estão sendo expandidas para outros segmentos, como os relacionados a bens duráveis, semiduráveis e têxteis, entre outros.

O crescimento dos supermercados no Brasil não é fato recente. Já em 1994/95 o Censo da Nielsen Serviços de Marketing apresentava o varejo tradicional com cerca de $85 \%$ do número total de lojas, mas ficando com apenas $15 \%$ do faturamento. O auto-serviço, por outro lado, em que os supermercados preponderam de forma absoluta, detinha $15 \%$ do número de lojas, mas concentrava 85\% do volume das vendas (Nielsen, 1995).

O auto-atendimento, inicialmente imaginado como forma de redução de custos, em função da menor utilização de mão-de-obra, trouxe novos elementos que modificaram o processo tradicional de compra. O consumidor, ao percorrer o estoque do varejista, passa a ter contato com um número de produtos muito superior ao que planeja comprar. E essa exposição, inexistente no atendimento de balcão, pode estimular a compra de itens extras. No ambiente do auto-serviço, o impulso para a compra não programada pode decorrer dos mais variados fatores, mas tanto os estudos acadêmicos, como os executivos de mercado, concordam com a sua existência (PROVAR, 2001).

O presente trabalho orienta-se pelas necessidades ocasionadas com a reorganização do varejo brasileiro, concentrando seu foco analítico no segmento de maior importância hoje no varejo brasileiro: os supermercados. O trabalho, baseado em pesquisa realizada pelo Programa de Administração de Varejo (PROVAR) no segundo semestre de 2001, tenta trazer uma contribuição ao melhor entendimento da compra por impulso, ou não planejada, nesse ramo do varejo e dos fatores que a determinam. Manter o cliente na loja, sujeito aos permanentes e variados argumentos de venda, parece ser algo que estimula a realização de gastos maiores. Por outro lado, a própria organização da loja pode instigar maior consumo. O propósito deste artigo é analisar os resultados da pesquisa do PROVAR e verificar o impacto nos gastos realizados pelos consumidores do tempo que as pessoas permanecem na loja e da organização da área de venda. Relativamente à arrumação da loja, podese considerá-la de diversas formas: organização, layout e iluminação, entre outras. Em relação a isto, este artigo trata de um aspecto específico, que é a colocação de produtos complementares próximos uns dos outros. 
Esse trabalho encontra-se organizado em três partes. A primeira faz uma revisão da literatura, procurando conceituar o que é denominado compra por impulso, ou não planejada. A segunda parte, referente ao método empregado na pesquisa, apresenta as características gerais da amostra utilizada e explicita o modelo analítico empregado. A última parte é reservada para uma síntese das principais idéias e apresentação das conclusões gerais.

\section{O Processo de Compra}

A teoria econômica tem dedicado grande atenção ao processo decisório de consumo por parte das pessoas. Toda a base da teoria microeconômica é construída sobre o pressuposto da racionalidade do consumidor. Supõe-se que as pessoas, condicionadas pelas respectivas restrições de renda, buscam maximizar a satisfação. Admite-se também que os consumidores, ao tomarem uma decisão, são capazes de realizar análises e comparações, de modo a tirar o maior proveito possível de cada uma das diferentes situações. A teoria econômica não estabelece distinção de produtos em sua concepção tradicional (Engel, Blakwell e Miniard, 1985). A revisão da literatura, apresentada a seguir, foi feita procurando-se contextualizar os diferentes enfoques no âmbito do mercado de produtos de consumo corrente.

Embora não de forma explícita, as idéias presentes na microeconomia suscitam uma ação de consumo razoavelmente planejada. Muitos estudos indicam, entretanto, que o comportamento de compra é, na verdade, bastante impulsivo, ou de outro modo, não planejado. Um estudo recente realizado pelo Point-of-Purchase Advertising Institute - POPAI (1998) revela que cerca de 85\% das decisões de compra são realizadas no interior da loja. Essa constatação parece estar em consonância com a prática varejista, que atribui grande importância às condições locais e momentâneas da compra.

Engel, Blakwell e Miniard (1995) analisam mais detalhadamente o processo de compra. Para os autores, a compra pode ser:

. totalmente planejada, quando tanto a marca quanto o produto são escolhidos com antecedência ao ato da compra no ponto de venda;

- parcialmente planejada, quando a escolha da marca é tomada no ponto de venda; e

- não planejada, quando a escolha do produto e da marca é realizada no ponto de venda. 
As compras totalmente planejadas dizem respeito geralmente a procedimentos repetidos e com baixo envolvimento emocional por parte do consumidor. De modo geral, o volume de compras para dado consumidor, sujeito a determinada restrição orçamentária, é "condicionado pela disponibilidade de tempo e pelas características físicas da loja: o seu layout” (Engel, Blakwell e Miniard, 1985, p. 155).

A compra parcialmente planejada pressupõe que apenas parte da compra é planejada, restando a escolha da marca para o ponto de venda. A decisão final, portanto, fica a critério de fatores situacionais no momento específico da compra, como promoções, displays, posição, disponibilidade ou embalagens especiais (Walters, 1991).

A compra não planejada é o formato de compra mais complexo de se conceituar, pois envolve uma amplitude de fatores subjetivos. Kollat e Willet (apud Engel, Blakwell e Miniard, 1985) entendem que compra por impulso é a compra realizada sem o conhecimento da necessidade antes da entrada da loja, tornando assim os termos relacionados a compras não planejadas e compras por impulso sinônimos.

D’Antoni e Shenson (apud Costa, 2001) discordam dos pontos de vista de Engels e de Kollat e Willet. Para estes autores, o fato da decisão de compra ser tomada, ou completada, no interior da loja não significa que a necessidade do bem já não estivesse previamente identificada. No caso da compra por impulso, a necessidade e o desejo da compra ocorreriam simultaneamente, suscitados pelo contato do consumidor com a disponibilidade do produto.

Para Rook (1987, p. 191) a compra por impulso ocorreria quando "um consumidor experimenta uma necessidade, persistente e muitas vezes poderosa, de compra repentinamente. $\mathrm{O}$ impulso de comprar é hedonicamente complexo e pode estimular conflitos de natureza emocional. Além disso, ocorre com reduzida preocupação com suas conseqüências”. Assim, quando o indivíduo se engaja em um comportamento impulsivo de compra, "há uma exacerbação de seus estados emocionais, havendo baixo controle intelectual sobre sua decisão" (Weinberg e Gottwald, 1982). A decisão passa a ser automática e todo o processo de busca e avaliação das alternativas é minimizado.

Beatty e Ferrel (apud Costa, 2001) compartilham do mesmo ponto de vista, entendendo que a compra por impulso se dá como aquisição imediata e repentina. Esse comportamento seria caracterizado basicamente por "atitudes espontâneas, resultantes de um particular estímulo”.

Stern (apud Costa, 2001) ampliou este conceito com base em sua tipologia de compra impulsiva. A classificação de Stern (1962) considera implicitamente a importância do estímulo propiciado pelo meio (varejo) na ocorrência da compra. 
Ainda para Stern (apud Costa, 1999), as compras não planejadas podem ser de três tipos:

. Reposição de itens, quando o consumidor não pensou em adquirir o item naquele exato momento, mas este é produto de uso habitual. Nesse caso, a ação de compra poderia ser desencadeada por uma condição especial, como, por exemplo, um desconto.

- Nova avaliação, quando as necessidades do consumidor se revelam na interação dele com sua exposição. Podem ser itens que já estão em uso, assim como produtos inéditos.

. Compra por impulso, que representa os casos extremos, em que o consumidor adquire o item espontaneamente e sem qualquer premeditação. A compra é resposta a um sentimento de urgência.

Piron (apud Costa, 2001) acredita que as reações emocionais e cognitivas do indivíduo podem acompanhar o comportamento de compra por impulso; porém não são condições essenciais, uma vez que não é necessário que o consumidor experimente tais sensações para adquirir um produto por impulso.

Em suma, pode-se perceber dois grupos distintos de entendimentos sobre a compra por impulso. Um primeiro que a associa à idéia de planejamento, imaginando que quanto maior o número de decisões (em termos de produtos e marcas) a serem feitas no interior da loja, maior a impulsividade do ato. Nesse grupo, com divergência de opiniões quanto à graduação necessária para caracterizar a compra por impulso, estão Engel, Blakwell e Miniard e Kollat e Willet. O segundo grupo, no qual se incluem Rook, Stern, Weinberg e Gottwald, Beatty e Ferrel e Piron, vê as compras por impulso como aquelas nas quais o processo decisório é fortemente influenciado por fatores emocionais. Apenas D’Antoni e Shenson, por adotarem uma definição mais estrita do fenômeno, não se encaixam em nenhum desses grupos, em que pese o fato de seu entendimento ser pouco prático.

A revisão da literatura mostrou que há muitas interpretações sobre o assunto. Para os fins deste trabalho, entretanto, é preciso adotar uma definição operacional. Para isso serão consideradas compras por impulso tanto aquelas que não foram planejadas - total ou parcialmente - quanto aquelas cujas decisões foram tomadas por critérios emocionais. Partindo desse pressuposto, o presente estudo preocuparse-á com o resultado do processo de compra. Assim, serão analisados dois grupos de indivíduos: os que gastam acima do planejado e os que gastam igual ou abaixo do valor planejado. 


\section{Método Empregado, Base de Dados e o Modelo Analítico}

Os dados utilizados no presente artigo foram extraídos de pesquisa realizada pelo Programa de Administração de Varejo (PROVAR) no segundo semestre do ano de 2001. O levantamento, que tinha por objetivo compreender melhor o comportamento de consumo dos indivíduos em supermercados, consistia em uma pesquisa de opinião com 35 perguntas.

Foram entrevistados consumidores adultos que deixavam supermercados e hipermercados, após realizarem suas compras, nas quatro regiões geográficas do município de São Paulo (Norte, Sul, Leste e Oeste). O total de indivíduos pesquisados foi de 420 pessoas. Seguindo-se a tendência aproximada da estratificação da população, revelada nos estudos do IBGE, 50\% das entrevistas foram feitas com homens e $50 \%$ com mulheres.

Em cada região da cidade foram sorteados supermercados e hipermercados em iguais quantidades e os entrevistadores receberam cotas de entrevistas a serem feitas em cada um deles. Embora a amostragem por cota não possa ser considerada probabilística, critério necessário para a realização de inferências para a população, na prática seus resultados são próximos, como tem sido observado nas pesquisas eleitorais. Assim, espera-se que os resultados da amostra sirvam como baliza do comportamento da população.

Como a maioria das perguntas era do tipo de resposta fechada, de caráter dicotômico, e não se conhecia a priori a dispersão da população, admitiu-se o pior caso possível para o dimensionamento da amostra, que é o de $50 \%$ de respostas positivas e 50\% negativas. Adotando-se um nível de acerto de 95,5\% no estabelecimento dos intervalos de confiança e um erro máximo 5\%, chegouse a um tamanho de amostra de 400 pessoas. Sendo a amostra muito menor do que a população, não foi necessário utilizar o fator de correção para populações finitas.

A fórmula utilizada para o cálculo do tamanho da amostra foi:

$$
\mathrm{n}=\frac{\text { P.Q. } \mathrm{Z}^{2}}{\mathrm{D}^{2}}
$$

onde:

- P é a estimativa da proporção populacional favorável a um resultado. No caso $\mathrm{P}=0,50$ (50\%). 
. Q = 1 - P é a estimativa da proporção dos desfavoráveis a um resultado da mesma questão. No caso $\mathrm{Q}=0,50$ (50\%).

. Z é a abscissa da distribuição normal padrão, fixado determinado nível de confiança. No caso $Z=2$, pois o nível de confiança foi de $95,5 \%$.

- D é o erro amostral, ou seja, a máxima diferença admitida entre $\mathrm{P}^{*}$ (a proporção real da população) e o P. No caso, D = 0,05 (5\%).

Considerando os propósitos do trabalho, separou-se inicialmente a amostra em dois subgrupos: os consumidores que gastaram acima do planejado ( $\mathrm{rz}=$ gasto efetivo/gasto planejado $>100$ ) e os consumidores que gastaram igual ou abaixo ao planejado (rz $<=100$ ). A Tabela 1 a seguir apresenta algumas informações descritivas gerais para cada um dos dois grupos.

\section{Tabela 1: Descrição dos Grupos - Gastos Maior e Menor Que o Planejado}

\begin{tabular}{l|l|l}
\hline Indicadores & $\mathrm{rz}>100(\mathrm{em} \%)$ & $\mathrm{rz}<=100(\mathrm{em} \%)$ \\
\hline Média & 138,36 & 82,05 \\
\hline Mediana & 130,00 & 87,00 \\
\hline Valor máximo & 250,00 & 100,00 \\
\hline Valor mínimo & 33,00 & 2,00 \\
\hline Desvio-padrão & 30,46 & 17,03 \\
\hline Número de observações $\left(^{*}\right)$ & 307 & 83 \\
\hline
\end{tabular}

Nota: $(*)$ duas observações foram excluídas, já que as respostas eram claramente inconsistentes.

Considerando que os gastos dependem das condições econômicas dos consumidores e também dos estímulos criados pela loja, especificou-se o seguinte modelo:

$\log (G)=c_{0}+c_{1}(T)+c_{2}\left(D_{0}\right)+c_{3}\left(D_{R 1}\right)+c_{4}\left(D_{R 2}\right)+c_{5}\left(D_{R 3}\right)+u$

onde:

. $\mathrm{G}$ = gasto efetivo declarado pelo consumidor.

. $\mathrm{T}=$ tempo total na loja (incluindo estacionamento).

. $\mathrm{D}_{0}$ = variável dummy relativa à questão: “Acho que a compra é facilitada quando produtos relacionados estão expostos um próximo do outro (exemplo macarrão e molho)". As respostas sim correspondem a $\mathrm{D}_{0}=1$; caso contrário, $\mathrm{D}_{0}=0$. 
- $\mathrm{D}_{\mathrm{R} 1}, \mathrm{D}_{\mathrm{R} 2}$ e $\mathrm{D}_{\mathrm{R} 3}$ são variáveis dummy e refletem quatro níveis de renda: $\mathrm{D}_{\mathrm{R} 1}=1$ se o respondente foi classificado na primeira faixa de renda familiar, ou seja, até $\mathrm{R} \$ 1.820,00$, caso contrário $\mathrm{D}_{\mathrm{R} 1}=0 ; \mathrm{D}_{\mathrm{R} 2}=1$ se o respondente declarasse renda na faixa de $\mathrm{R} \$ 1.821,00$ a $\mathrm{R} \$ 3.642,00$, caso contrário $\mathrm{D}_{\mathrm{R} 2}=0 ; \mathrm{D}_{\mathrm{R} 3}=1$ se o entrevistado fosse classificado na terceira faixa, de $\mathrm{R} \$ 3.643,00$ a $\mathrm{R} \$ 7.280,00$, caso contrário $\mathrm{D}_{\mathrm{R} 3}=0$. É importante observar que a última faixa, acima de $\mathrm{R} \$ 7.281,00$, é representada pelo intercepto da regressão.

. u = termo aleatório.

. $\mathrm{C}_{0}, \mathrm{C}_{1}, \mathrm{C}_{2}$ e $\mathrm{c}_{3}=$ coeficientes.

É de se esperar, evidentemente, que quanto maior a renda, maiores devem ser os gastos. Como o intercepto representa a faixa de maior renda, esperase que todos os coeficientes das variáveis do modelo se apresentem com sinal negativo. A variável tempo deve apresentar coeficiente positivo, dado que quanto mais o consumidor estiver exposto aos argumentos de venda, maiores devem ser seus gastos. Imagina-se, também, que a organização da loja, com produtos complementares colocados próximos, deve aumentar a tendência dos gastos.

O modelo foi estimado utilizando a versão 4.0 do software E-Views em dois modelos: um para o grupo das pessoas que gastou mais que o planejado ( $\mathrm{rz}>100)$ e outro para o grupo dos que gastaram igual ou abaixo do valor planejado ( $\mathrm{rz}<=100$ ). Considerando tratar-se de dados em cross-section, resolveu-se proceder à correção de White (Manual E-Views, 2001).

\section{Apresentação dos Resultados}

Analisando-se os resultados apresentados nas Tabelas 2 e 3, pode-se verificar a sua consistência. Observa-se inicialmente que, como esperado, todos os coeficientes das variáveis dummies representantes da renda, aparecem com sinal negativo, indicando que essas faixas consomem menos que a última, a mais elevada. O poder explicativo das regressões é razoável para estudos dessa natureza, com tantas variáveis interferindo no processo de escolha. Nos dois modelos, a distribuição dos resíduos revelou-se normal, conforme teste Jarque-Bera (Manual E-Views, 2001). O valor do teste DW demonstra também a inexistência de autocorrelação serial positiva. 
Tabela 2: Resultados para rz $>100$

\begin{tabular}{c|c|c}
\hline Variáveis & Coeficiente & Tc \\
\hline $\mathrm{C}_{0}$ & 3,7027 & 32,9568 \\
\hline $\mathrm{T}$ & 0,0133 & 14,9416 \\
\hline $\mathrm{D}_{0}$ & 0,1313 & 1,7200 \\
\hline $\mathrm{D}_{1}$ & $-0,4146$ & $-2,0502$ \\
\hline $\mathrm{D}_{2}$ & $-0,2197$ & $-2,3802$ \\
\hline $\mathrm{D}_{3}$ & $-0,0686$ & $-0,9383$ \\
\hline $\mathrm{R}^{2}$ & 54,1746 & - \\
\hline $\mathrm{R}^{2}$ Ajustado & 53,4149 & - \\
\hline $\mathrm{DW}$ & 0,9558 & - \\
\hline Número de observações & 308 & - \\
\hline
\end{tabular}

Nota: Tc = estatística $\mathbf{t}$ de Student.

Tabela 3: Resultados para $\mathbf{r z}<=100$

\begin{tabular}{c|c|c}
\hline Variáveis & Coeficiente & Tc \\
\hline $\mathrm{C}_{0}$ & 3,1686 & 14,8534 \\
\hline $\mathrm{T}$ & 0,0204 & 7,9987 \\
\hline $\mathrm{D}_{0}$ & $-0,3953$ & $-2,0356$ \\
\hline $\mathrm{D}_{1}$ & $-0,5414$ & $-1,8494$ \\
\hline $\mathrm{D}_{2}$ & $-0,2444$ & $-1,1324$ \\
\hline $\mathrm{D}_{3}$ & $-0,0282$ & $-0,1256$ \\
\hline $\mathrm{R}^{2}$ & 57,3000 & - \\
\hline $\mathrm{R}^{2}$ Ajustado & 54,7882 & - \\
\hline $\mathrm{DW}$ & 1,3325 & - \\
\hline Número de observações & 91 & - \\
\hline
\end{tabular}

Nota: Tc = estatística $\mathbf{t}$ de Student.

Nota-se que a variável tempo é bastante sensível na explicação do gasto, indicando que, quanto maior o tempo de exposição do consumidor aos argumentos de venda disponíveis na loja, maior o gasto.

Um resultado que merece destaque é o valor do coeficiente da variável dummy que representa a organização da loja. Observa-se que para rz $>100$, essa é significativa a pouco mais de $8 \%$, indicando que a organização da loja com produtos complementares próximos estimula o consumo. O mesmo não se verifica no caso do conjunto composto pelas observações que obedecem à restrição rz $<=100$. O coeficiente apresenta-se com o sinal trocado e é significativo a 5\%. De outra maneira, no grupo das pessoas que gastaram igual ou abaixo do planejado a proximidade de produtos não contribuiu para ampliar os gastos. Há indícios, portanto, de que o sentido é mesmo oposto, ou seja, pelo fato de a loja estar 
organizada, o gasto é menor. Esse resultado por certo é interessante e sugere algum trabalho adicional.

A tabulação dos dados da pesquisa de campo realizada pelo PROVAR e o cruzamento de alguns dos seus resultados mostraram que a compra por impulso é afetada pelos seguintes resultados:

- Renda: a média observada para toda a amostra gira em torno de $20 \%$, mas atinge patamares de 30\% para os níveis de renda superiores a R \$7.280,00 (40 salários mínimos).

- Tempo de loja: a média de gasto por minuto de loja ficou em torno de R\$2,00, porém atingiu a cifra de $\mathrm{R} \$ 3,12$ para a faixa de renda acima de 40 salários mínimos.

Além dos resultados apresentados na regressão analisada, um estudo realizado pelo PROVAR (2001) mostra que outras variáveis são explicativas do comportamento de gasto por parte dos consumidores no ponto de venda, a saber:

- Lista de compras: em todos os cruzamentos realizados, verificou-se que a ausência de lista de compras acarretou em maiores erros na previsão do gasto com as compras, o que sugere que esse procedimento torne o consumidor mais exposto ao impulso de comprar de forma não muito racional.

- Experiência de compras: à medida que o consumidor se torna mais experiente com as compras em supermercado, ele aprende a ignorar os estímulos gerados pelos varejistas e fica menos vulnerável à compra por impulso.

- Idade: a idade do consumidor é variável relacionada à ocorrência de compras por impulso; de forma geral, quanto mais jovem, mais suscetível a elas está o consumidor.

- Natureza do produto: a pesquisa revelou que os itens em que há maior ocorrência das compras impulsivas são, em ordem decrescente: (1) baterias, pilhas e filmes fotográficos; (2) salgadinhos; (3) doces; (4) produtos de limpeza; (5) produtos de beleza; e (6) produtos de higiene básica.

- Apreço por novidade: os indivíduos que afirmaram sentir prazer em provar novidades, compram por impulso em bases mais freqüentes que os demais.

- Acompanhante: os filhos seguidos pelos cônjuges foram os mais citados (com $58,8 \%$ e $26,2 \%$, respectivamente) como responsáveis pela indução a compras não planejadas. 
Com a utilização da técnica da regressão linear múltipla, após dividir os dados em dois conjuntos - os que gastaram mais que o planejado e os que gastaram igual ou abaixo do planejado - construíram-se dois modelos. Ficou evidenciada a importância do tempo em que o consumidor permanece na loja, para explicar as oscilações dos gastos nos dois grupos. Quanto à organização dos produtos, observou-se que no grupo dos que gastam menos que o planejado a percepção da melhor organização não contribui para que o consumidor aumente seus gastos.

\section{Conclusões}

O varejo brasileiro tem passado por profundo processo de transformação. A estabilidade da economia tem obrigado as empresas comerciais brasileiras a se tornarem mais competitivas. A maior consciência de preços por parte dos consumidores, aliada à queda das receitas financeiras e ao ingresso de redes estrangeiras no mercado, exigem nova postura administrativa de todas as empresas operantes (Korgaonkar, 1981) nos mais diversos segmentos do varejo brasileiro.

O ramo dos supermercados tem particular importância, uma vez que o peso desse segmento na comercialização de bens no Brasil não só é muito elevado, como também crescente. É por essa razão que o presente trabalho abordou o comportamento de consumo nos supermercados, sob a ótica da compra por impulso. Procurou-se compreender melhor a sensibilidade aos gastos em função do tempo despendido nas lojas, assim como a percepção do consumidor relativamente à maneira como os produtos são dispostos.

A pesquisa realizada pelo PROVAR no segundo semestre de 2001 mostrou que, quanto maior a disponibilidade de renda, maior o nível de gasto por minuto de permanência no supermercado e maior o erro na previsão do gasto. Além disso, os resultados são embasados pelas indicações de que o tempo em que o consumidor permanece dentro da loja é fator relacionado com o nível de gasto que ele realiza, assim como a sua experiência no processo de compra no estabelecimento em questão, a sua idade e a natureza do produto a ser comprado. Ademais, o fato de ter sido preparada antecipadamente uma lista de compra, de estar acompanhado pelos filhos e o apreço por novidades também afetam o nível de gasto.

Com os resultados apresentados, testou-se o grau de sensibilidade dos consumidores aos gastos em termos da renda, do tempo consumido nas lojas e da sua opinião quanto à organização dos produtos nos corredores e gôndolas. Na realidade, o presente trabalho evidenciou uma relação inversa, já que as pessoas incluídas no grupo em que $\mathrm{rz}<=100$ e que opinaram afirmativamente quanto a 
apreciarem a disposição de produtos complementares próximos, tendem a gastar menos.

O assunto referente a compras por impulso é amplo e envolve várias áreas do conhecimento. Com este trabalho, os autores esperam ter contribuído para a melhor compreensão desse fenômeno, principalmente no que diz respeito à realidade brasileira. Certamente estudos futuros complementarão e aperfeiçoarão os resultados aqui apresentados.

\section{Referências Bibliográficas}

BEATTY, S.;

FERELL, E.

Impulse buying: modeling its precursors. Journal of Retailing, v. 74, n. 2, p. 169-192, Summer 1998.

\section{BLECHER, N.}

Quer preço ou quer marca?

Revista Exame, ano 35, n. 12, p.

32, 2001.

COSTA, F. C. X.

Influências ambientais no comportamento de compra por impulso: um estudo exploratório. In: Varejo competitivo. São Paulo: Atlas, 2001. v. 6. p. 225247.

E-VIEWS.

User's guide 4.0. 2001.

ENGEL, G;

BLAKWELL, R.;

MINIARD, $\mathrm{P}$.

Consumer behavior. 8.ed. New York: Irwin, 1995.
KORGAONKAR, P. K.

Shopping orientations, importante of store attributes, demographics and store patronage: a multivariate investigation. Business and Economic Review, v. 12, n. 4, Winter 1981.

NIELSEN.

Censo Nielsen de Serviços de Marketing de 1994/1995. 1995.

PIRON, F.

Defining impulse purchase: advances in consumer research. Association for Consumer Research, p. 509-514, 1987.

POPAI.

Point-of-Purchase Advertising Institute. In: 1., ESTUDO SOBRE O COMPORTAMENTO DO CONSUMIDOR NO PONTO-DE-VENDA, 1998, [S.l.]. 


\section{PROVAR.}

O comportamento de consumo nos supermercados. Programa de Administração de Varejo FIAFEA/USP. 2001.

ROOK, D. W.

The buying impulse. Journal of Consumer Research, v. 14, p. 189-199, Sept. 1987.

\section{STERN, H.}

The significance of impulse buying today. Journal of Marketing, v. 26, p. 59-62, Apr. 1962.
WALTERS, R. G.

Assessing the impact of retail price promotions on product substitution, complementary purchase, and interstore sales displacement. Journal of Marketing, v. 55, n. 2, p. 17-21, Apr. 1991.

WEINBERG, P.; GOTTWALD, W.

Impulsive consumer buying as a result of emotions. Journal of Business Research, v. 10, n. 1, Mar. 1982. 